Finance and Economics Discussion Series Divisions of Research \& Statistics and Monetary Affairs Federal Reserve Board, Washington, D.C.

\title{
Monetary Policy and the Information Content of the Yield Spread
}

\section{Michael Feroli}

2004-44

NOTE: Staff working papers in the Finance and Economics Discussion Series (FEDS) are preliminary materials circulated to stimulate discussion and critical comment. The analysis and conclusions set forth are those of the authors and do not indicate concurrence by other members of the research staff or the Board of Governors. References in publications to the Finance and Economics Discussion Series (other than acknowledgement) should be cleared with the author(s) to protect the tentative character of these papers. 


\title{
Monetary Policy and the Information Content of the Yield Spread
}

\author{
Michael Feroli* \\ Federal Reserve Board \\ Division of Research and Statistics
}

August, 2004

\begin{abstract}
This paper demonstrates that the ability of the yield spread to predict output fluctuations is contingent on the monetary authority's reaction function. In particular, expectations of monetary policy actions are crucial for the spread to predict output conditional on the short-rate. Furthermore, numerical experiments suggest that the post-1979 decrease in the yield spread's predictive power is due to a shift in the monetary policy reaction function at that time.
\end{abstract}

Keywords: Yield Spread, Business Cycles, Monetary Policy.

JEL Classification: E37, E43, E52.

${ }^{*}$ The views expressed in this paper are those of the author and do not represent those of the Federal Reserve System or its staff. Corresponding address: 20th St. \& Constitution Ave., NW, Mail Stop 80, Washington, D.C. 20551. E-mail:Michael.E.Feroli@frb.gov 


\section{Introduction}

Following Laurent (1988) and Stock and Watson (1989), a flurry of papers in the early '90s empirically tested and verified the well-known proposition that a flattening of the yield curve is a strong signal of an impending recession. Though different studies use different maturities for the long and short rates, generally the same result obtains: the yield spread significantly predicts GDP for horizons from one to eight quarters ahead. In fact, for forecast horizons of greater than two quarters Estrella and Mishkin (1996) show that the yield spread considerably outperforms specially constructed indices such as the Commerce Department's index of leading economic indicators.

In this paper we will review the evidence of the predictive power of the yield spread and examine what it tells us about commonly told stories concerning the relation between the yield spread and future output. In particular, we examine the explanation which proceeds as - "A rise in the short-term rate (usually due to tightening by the central bank) will flatten the yield curve as well as slow real growth. Hence, a flatter yield curve will precede a slowdown in output." As we will see, however, when the short-rate or other measures of the policy stance of the monetary authority are included on the right-hand-side of an output forecasting equation, the yield spread generally retains its significance, thus casting some doubt on the sufficiency of the above-mentioned explanation. Motivated by these empirical findings, we seek to provide an analytical examination of the predictive power of the yield spread and to demonstrate that this power is dependent on the functional form and parameter values of the monetary authority's policy reaction function. We then provide a set of numerical experiments in order to understand the quantitative significance of shifts in monetary policy for this predictive power.

The analytical investigation reveals that two elements are crucial for the spread to contain information about future output, (i) interest smoothing, and (ii) a counter-cyclical response of monetary policy, meaning a positive interest rate reaction to either inflation or output deviations. In brief, the intuition is as follows: in the presence of interest smoothing 
the difference in one-period rates becomes an instrument of monetary policy. When the central back reacts to macroeconomic conditions, this instrument is reflective of central bank expectations regarding the future path of output and inflation. Since the yield spread can be written as the difference of one-period rates, it is only an exercise in algebra to demonstrate that the central bank's expected future path of output is, in some sense, contained in the yield spread.

The results of the Monte Carlo experiments suggest that the monetary policy explanation of the yield curve's predictive ability does a good job in matching up with some of the key facts. Naturally, the most important fact any model should replicate is having the spread Granger cause output. Additionally, the model is able to reproduce two further results that are also interesting:

(1) As mentioned above, and emphasized in Estrella and Hardouvelis (1991), in VAR's that also include a short-term rate such as the federal funds rate, the yield spread retains its significance as a predictor of output.

(2) When examined in different periods, Dotsey (1998) and others find the yield spread's ability to signal output becomes much weaker from the '80s to the present.

Result (1) is striking given that the standard informal explanation of the spread's predictive power alluded to earlier relies on the short-term rate both to flatten the yield curve as well as to slow real growth. The fact that the yield curve has predictive power over and above that contained in the short rate considerably complicates any explanation of this power.

Result (2), while not necessarily pointing to monetary policy, at least suggests that whatever explanation of the predictive significance of the yield spread is offered, that explanation should, in some way, depend upon structural parameters that are possibly varying over time. Clarida, Gali, and Gertler (2000) find that the structural parameters governing the monetary reaction function changed significantly after Paul Volcker became Chairman of the Federal Reserve in the third quarter of 1979. This is the same period in which Estrella, 
Rodrigues, and Schich (2000) find a structural break in the predictive ability of the yield spread measured as both a decline in the slope coefficient and a decline in the $R^{2}$ of the yield spread regression. These observations motivate the numerical experiments which are conducted later in this paper. Specifically, we construct a small-scale dynamic macro model under two alternative sets of parameterizations: the first with the estimated Taylor rule before Volcker became Chairman and the second with the estimated Taylor rule after Volcker became Chairman. We find that, consistent with the data, the simulated predictive power of the yield spread declines when the monetary authority adopts a policy rule consistent with that estimated for the post-1979 period.

The rest of the paper is organized as follows: Section 2 reviews the evidence on the relation between the yield curve, monetary policy, and future output, Section 3 explains some of these observed facts through a small-scale macro model and various specifications of the policy reaction function, Section 4 provides some numerical experiments to examine the predictive power of the yield spread under different monetary policy regimes. Section 5 offers a few concluding remarks.

\section{Empirical Results}

Before proceeding to the analytical investigation, it is useful to here review some of the empirical findings. Consider, for example, the results for the following regression which is very common in the empirical literature, (see for example Hamilton and Kim (2000), to cite only one recent example):

$$
(400 / k) *\left(\log y_{t+k}-\log y_{t}\right)=\alpha+\beta_{1} S_{t}+\beta_{2} i_{t}+\epsilon_{t},
$$

where $y_{t}$ is real GDP, $S_{t}$ is the yield spread, and $i_{t}$ is the short-rate. For the spread we look at the three-year less three-month treasury security constant maturity rate. The shortrate considered is the federal funds rate. For ease of exposition we only consider $k=4$, or the one-year ahead cumulative output forecast. The sample runs from 1962:Q1 to 2004:Q1. 
The standard errors are corrected for autocorrelation using the method of Newey and West (1987), and the results are reported in table (1).

As mentioned in the introduction, a common explanation for the yield spread's predictive power proceeds as: (i) the Fed, say, tightens, (ii) the yield spread decreases, or turns negative, and (iii) through the aggregate demand channel of monetary transmission, future output falls. As can be seen in table (1), the federal funds rate clearly Granger causes ${ }^{1}$ future output, lending credence to the above story. However, the fact that the spread enters the above regression significantly even conditional on the federal funds rate suggests the above story is not entirely capturing the mechanism behind the yield spread's ability to predict output.

It could be argued that, in fact, the above story explains entirely the significance of the spread in output forecasting equations but that the spread retains spurious significance because the federal funds rate is a poor measure of monetary policy. To test this we substitute three separate measures of the stance of monetary policy in place of the federal funds rate in the previous baseline regression: the first difference of the federal funds rate, residuals from an identified VAR that are commonly thought to be associated with monetary policy innovations, and a narrative measure of the monetary policy stance. The results from the regression using first-differences of the federal funds rate are reported in table (2a). For the residual-based measure of monetary policy, we estimate a recursive VAR ordered as: real GDP, real GDP deflator, and the federal funds rate. We take the residuals from the last equation as our measure of monetary policy. The regression results from using this measure of monetary policy are reported in table $(2 \mathrm{~b})$. Finally, we use as a narrative measure of monetary policy the Boschen and Mills (1995) index in the above regression and report the results in table (2c).

As can be seen in tables (2a) through (2c), whichever measure of the current monetary policy stance is used, the yield spread retains its significance as a predictor of future output. Of course, all of these measures of monetary policy are imperfect. Nevertheless, the fact

\footnotetext{
${ }^{1}$ Because the standard empirical regression does not include lagged values of the spread, the Granger causality test reduces to a t-test of significance on the spread.
} 
that the spread enters significantly regardless of which policy measure we employ is highly suggestive that the spread is not merely picking up information about current monetary policy. As we will see in the next section, this does not mean monetary policy does not play

a central role in the predictive power of the yield spread, but rather, expectations of future monetary policy, which are not captured in the fed funds rate or other indicators of current monetary policy, play a crucial role in the spread's predictive abilities.

As an aside it is interesting to note that all of our alternative measures of monetary policy are correctly signed, but only the narrative measure has significance as a predictor of future output.

Finally, as was discussed in the introduction, several authors have recently found sample instability in the predictive ability of the yield spread. Table (3) reports the results of our baseline regression when the sample is split in the third quarter of 1979. In the second half of the sample, the coefficient of determination and the coefficient on the spread decline considerably from the first half of the sample.

\section{A Small Model}

The following section seeks to demonstrate that a model with a simple monetary policy rule can generate predictive power of the yield curve. The core of the model is constructed by integrating two economic hypotheses: i) the long bond rate is a function only of the sequence of future one period interest rates and ii) one period interest rates are controlled by the monetary authority and react to variables in the macroeconomy. In other words, we assume the Pure Expectations Hypothesis and the Taylor rule. These assumptions can be represented, respectively, by,

$$
\begin{aligned}
i_{t}^{N} & =\frac{1}{N} E_{t}\left(i_{t}^{1}+i_{t+1}^{1}+i_{t+2}^{1}+\ldots+i_{t+N-1}^{1}\right) \\
i_{t}^{1} & =\rho i_{t-1}^{1}+(1-\rho)\left[i^{*}+\beta\left(E_{t} \pi_{t, k}-\pi^{*}\right)+\gamma E_{t} y_{t, q}\right]
\end{aligned}
$$


Here $i_{t}^{m}$ is the nominal interest rate on an $m$-period bond purchased at time $t, i^{*}$ and $\pi^{*}$ are the monetary authority's target nominal interest rate and inflation rate, and $E_{t} \pi_{t, k}$ and $E_{t} y_{t, q}$ are, respectively, the expectations of the inflation rate $k$ periods ahead and the output gap $q$ periods ahead. The inclusion of an interest smoothing term, $\rho$, in the above Taylor rule follows Clarida, Galí, and Gertler (2000). Consider now, for simplicity, the spread on a two-period less one-period bond,

$$
\begin{aligned}
S_{t}^{2,1} & =i_{t}^{2}-i_{t}^{1}, \\
S_{t}^{2,1} & =\frac{1}{2}\left(E_{t} i_{t+1}^{1}-i_{t}^{1}\right) .
\end{aligned}
$$

Assume $k$ and $q$ both equal 0 . Now, iterate equation (3) forward one period and subtract $(1-\rho) i_{t}^{1}$, employ equation (4) and use the Law of Iterated Expectations in order to arrive at,

$$
S_{t}^{2,1}=\frac{(1-\rho)}{2}\left[i^{*}+\beta E_{t}\left(\pi_{t+1}-\pi^{*}\right)+\gamma E_{t} y_{t+1}-i_{t}^{1}\right] .
$$

Rearranging gives the desired result,

$$
E_{t} y_{t+1}=\frac{2}{(1-\rho) \gamma} S_{t}^{2,1}-\frac{1}{\gamma}\left[i^{*}+\beta E_{t}\left(\pi_{t+1}-\pi^{*}\right)-i_{t}^{1}\right]
$$

Given rational expectations of both the central bank and the bond-holding public, the right hand side of equation (6) represents the true expected value of one-period-ahead output. If we let $\varepsilon_{t}^{\pi}$ and $\varepsilon_{t}^{y}$ denote the inflation and output expectational error, the we can re-write equation (6) as

$$
y_{t+1}=\frac{2}{(1-\rho) \gamma} S_{t}^{2,1}-\frac{1}{\gamma}\left[i^{*}+\beta\left(\pi_{t+1}-\pi^{*}\right)-i_{t}^{1}\right]+\varepsilon_{t}^{y}+\frac{\varepsilon_{t}^{\pi}}{\gamma} .
$$

Due to the endogeneity of the right hand side variables, equation (7) cannot be estimated by OLS. Moreover, the presence of future inflation on the right hand side makes it problematic to use equation (7) as a forecasting equation. As we will see in the next sec- 
tion, in practice the future inflation term is dropped and the omitted variable bias is often essentially ignored.

On the other hand, if we are to assume a Phillips curve relation between inflation and output (as we will do in the simulated model in the next section), then we will be able to substitute this relation, $\pi_{t}=\lambda y_{t}+\delta E_{t} \pi_{t+1}$, into equation (6) to arrive at

$$
E_{t} y_{t+1}=\frac{2}{(1-\rho)(\beta \lambda+\gamma)} S_{t}^{2,1}-\frac{1}{\gamma}\left[i^{*}+\beta E_{t}\left(\pi_{t+2}-\pi^{*}\right)-i_{t}^{1}\right]
$$

Note from equation (5) that for the spread to be a predictor of output in this model where we assume a Phillips curve relation, $\beta$ or $\gamma$ must be non-zero. This result should be obvious; for a linear combination of short-term interest rates, which are controlled by the monetary authority, to contain any information about the future path of output it is necessary for the monetary authority to set those rates with an eye toward dampening future fluctuations in the economy. Note also that as $\rho \rightarrow 0$, i.e. the central bank does not smooth short-term interest rates, and equation (6), using the relation in equation (4), reduces to

$$
E_{t} y_{t+1}=\frac{1}{\gamma} E_{t} i_{t+1}^{1}-\frac{1}{\gamma}\left[i^{*}+\beta E_{t}\left(\pi_{t+1}-\pi^{*}\right)\right] .
$$

Future output now depends on the level of the future one-period interest rate, while the spread, a term involving the difference in rates, drops out. For estimation purposes, however, the spread may remain significant insofar as it contains information about future one-period rates.

The dependence of equation (7) on the policy parameters is similar to the results obtained by Estrella (1998). However, Estrella generates his results by solving a system of five equations whereas with two equations we are able to show by hand the relation between the yield curve's predictive power and monetary policy. The benefit of this simplicity is that the intuition behind the result should be more readily apparent. We can then see how this intuition lines up with the casual explanations of the yield curve's predictive significance. 
Our story relating the yield spread, monetary policy and future output proceeds as: the Fed, say, hikes rates and thus (i), a recession ensues in which expectations of future output gaps (as well as future inflation) fall and therefore (ii), expected future rates fall thus flattening the yield curve. The first step relies on the logic of aggregate demand. However, as mentioned earlier, this effect would be captured in the short-rate alone while the spread is a significant predictor even conditioning on the short-rate. The second step implicitly makes a link with expectations concerning monetary policy. What the model makes explicit is our story's implied dependence on the monetary authority's reaction function. Ideally, the model adds to the conventional story's understanding of the predictive power of the yield spread by underscoring the importance of expectations of future monetary policy.

The fact that conditioning on the short-rate should control for the aggregate demand effect of monetary policy highlights another distinction from Estrella's framework. Our results are not dependent on a specification for how the macroeconomic variables are determined. Thus the yield spread should have predictive ability regardless of, for example, a particular representation of aggregate supply and demand. In fact, the result should hold even in an economy where output is driven solely by real shocks and monetary policy has no real effects. $^{2}$ So long as the short rate is positively related to output, the spread will contain information about future output. Importantly, the model also explains why the yield curve would predict recessions that aren't monetary in nature. Whether non-monetary disturbances are an important cause of recessions in the post-war U.S., however, is a matter of some debate. ${ }^{3}$ Nevertheless, the fact that the predictive content is robust to macroeconomic specifications could be viewed as a strength of the model.

\footnotetext{
${ }^{2}$ The existence of a Taylor rule in an economy where monetary policy has no effect on output is an admittedly odd extreme, though not completely absurd in, say, the context of optimal risk sharing. See, for example, Allen and Gale (1998).

${ }^{3}$ See the discussion in Temin (1998) and Romer (1998).
} 


\subsection{Yield Spreads at Longer Horizons}

This subsection will seek to demonstrate that extending the above analysis to maturities greater than two will add some complexity yet the primary results will still hold. Recall that the yield on an $N$-period bond can be written,

$$
i_{t}^{N}=\frac{1}{N} E_{t}\left(i_{t}^{1}+i_{t+1}^{1}+i_{t+2}^{1}+\ldots+i_{t+N-1}^{1}\right)
$$

Substituting in the Taylor rule and subtracting the short rate gives us,

$$
\begin{aligned}
S_{t}^{N, 1}= & \frac{1}{N}\left[i_{t} \cdot \frac{\left(1-\rho^{N}\right)}{(1-\rho)}+i^{*}\left\{(N-1)-\frac{\left(\rho-\rho^{N}\right)}{(1-\rho)}\right\}+\ldots\right. \\
& \left.\beta E_{t} \sum_{j=0}^{N-1}\left(1-\rho^{N-j}\right)\left(\pi_{t+1+j}-\pi^{*}\right)+\gamma E_{t} \sum_{j=0}^{N-1}\left(1-\rho^{N-j}\right) y_{t+1+j}\right]-i_{t} .
\end{aligned}
$$

All the major results from the previous analysis carry through here with little modification. If there exist securities $i_{j, t}$ for all $1 \leq j \leq N$ then it is theoretically possible to bootstrap an entire path of expected future output to time $t+N$ such that given predicted values of the output gaps $\widetilde{y}_{t+h}$ for $1 \leq h \leq N-1$ then we can express the predicted output gap for period $N$ as,

$$
\begin{aligned}
E_{t} y_{t+n}= & \frac{1}{(1-\rho)}\left[\frac { 1 } { \gamma } \left\{N \cdot\left(S_{t}^{N, 1}+i_{t}\right)-i_{t} \cdot \frac{\left(1-\rho^{N}\right)}{(1-\rho)}-i^{*}\left\{(N-1)-\frac{\left(\rho-\rho^{N}\right)}{(1-\rho)}\right\}-\ldots\right.\right. \\
& \left.\left.\beta E_{t} \sum_{j=0}^{N-1}\left(1-\rho^{N-j}\right)\left(\pi_{t+1+j}-\pi^{*}\right)\right\}-\gamma E_{t} \sum_{j=0}^{N-2}\left(1-\rho^{N-j}\right) \widetilde{y}_{t+1+j}\right] .
\end{aligned}
$$

This expression demonstrates that there is still a link between output and the spread at longer horizons.

\section{Simulation Exercises}

In this section we test the plausibility of the monetary policy rule interpretation of the predictive power of the yield curve. To do so we construct a parsimonious macro model and 
examine whether it can reproduce some of the key stylized facts about the relationship between the yield curve and future output. Among these facts are i) the yield spread consistently has a significantly positive coefficient in regressions of future output on the spread ii) this significance remains when the short term interest rate is also included in the regression and iii) the size of this positive coefficient as well as of the coefficient of determination has generally decreased over the past two decades.

In order to examine the behavior of our model we subject it to a sequence of fundamental shocks. The model will then produce endogenously determined time series' for output, inflation, and interest rates (both long- and short-rates). With this simulated data in hand we can then perform regressions that mirror those performed in the empirical literature and compare the simulated to estimated coefficients.

The framework in which we will analyze the dynamic responses of the economy is the baseline New Keynesian model. The two equations that determine the model correspond to the IS curve and the Phillips curve ${ }^{4}$ of the traditional Keynesian specification:

$$
\begin{aligned}
& y_{t}=-\varphi\left[i_{t}^{1}-E_{t} \pi_{t+1}\right]+E_{t} y_{t+1}+g_{t}, \\
& \pi_{t}=\lambda y_{t}+\delta E_{t} \pi_{t+1}+u_{t},
\end{aligned}
$$

where $y_{t}$ is the output gap, or the difference between actual and potential output, $\pi_{t}$ is the inflation rate and $i_{t}^{1}$ is the nominal one-period interest rate. The benchmark parameter values for equations (10) and (11) are from Clarida, Gali and Gertler (2000): $\varphi=1, \lambda=0.3$,and $\delta=.99$. These two equations, along with the Taylor rule, equation (3), determine the endogenous response of output, inflation and interest in response to the shocks $g_{t}$ and $u_{t}$.

The system (10), (11), and (3) is solved using the method of Blanchard and Khan (1980). Each simulation begins with draws from $u_{t}$ and $g_{t}$ of length 160 (corresponding to the 40

\footnotetext{
${ }^{4}$ The microfoundations of the New Keynesian model recommend the forward-looking behavior of inflation specified in the baseline model. However, this formulation has come under assault for its ability to describe inflation. As a check, we perform the same exercises under a backward-looking specification. In general, the findings are robust to whichever Phillips curve is used. In particular, the three factual criteria mentioned in the text are met under both specifications.
} 
years worth of data against which the model will be compared). The properties of the series $g_{t}$ and $u_{t}$ in the New Keynesian model are taken from Ireland (2001) and are modeled as $\mathrm{AR}(1)$ processes with autoregressive parameters of 0.94 and 0.92 , respectively, and standard deviations of 0.03 and 0.02 .

From these fundamental shocks, all the endogenous variables in the economy are determined. The long-bond rate in each period is determined under the Pure Expectations Hypothesis assuming perfect foresight. Future output is then regressed on the spread. This exercise is repeated 300 times and the average coefficient and its Newey-West corrected p-value are reported.

The simulated regressions are performed under two alternative calibrations of the Taylor rule. These parameters are taken from Clarida, Gali and Gertler (2000) who examine how the monetary reaction function shifted after Volcker was appointed Chairman of the Federal Reserve in 1979. Below we re-state equation (3) and give the parameters estimated for the two policy regimes,

$$
i_{t}^{1}=\rho i_{t-1}^{1}+(1-\rho)\left[i^{*}+\beta\left(E_{t} \pi_{t, k}-\pi^{*}\right)+\gamma E_{t} y_{t, q}\right]
$$

\begin{tabular}{|c|c|c|c|}
\hline & $\rho$ & $\beta$ & $\gamma$ \\
\hline Pre-1979 & 0.68 & 0.83 & 0.27 \\
\hline Post-1979 & 0.79 & 2.15 & 0.93 \\
\hline
\end{tabular}

Because a value of $\beta$ less than 1 would generate instability (see the discussion in Clarida, Gali and Gertler) we use 1.01 for $\beta$ in the Pre-Volcker calibration. Below we present the regression results on both the actual and simulated data.

In table (3) we re-ran the baseline regression while splitting the sample period in the third quarter of 1979, when Paul Volcker became chairman of the Federal Reserve. As can be seen in table (3), in the data the yield spread is a significant predictor of one-year ahead output, this significance is retained when the short-rate is included in the regression, and the strength of the yield spread as a signal of future output has decreased since 1979. 
In the simulated model presented in table (4), the yield spread also retains its predictive significance when controlling for the short-rate. Furthermore, the predictive signal given by the yield spread weakens after the Taylor rule shifts from pre-Volcker to Volcker-Greenspan parameters. Comparing the simulated regressions to those run on the data, the coefficients are all signed correctly and appear to be in the right ballpark in terms of magnitude. The simulated $R^{2}$ in all cases shows a similar decline following the shift in monetary policy regimes. Thus, the simulated evidence seems to suggest that the Taylor rule explanation of the yield spread's predictive power, in conjunction with the estimated shift in the parameters of the monetary reaction function, can account for the decline in the spread's predictive ability.

In table (5) we report the simulated regression results changing only one Taylor term at a time going from the pre-Volcker period to the Volcker-Greenspan period. All three Taylor parameters increase in magnitude as we move to the later regime. The change in the coefficients on the spread following the change in $\rho, \beta$ and $\gamma$ are consistent with what we would expect from equation (8).

\section{Conclusion}

Monetary policy affects whether, and to what extent, the yield spread can provide an independent signal of future output fluctuations. It is worthwhile to here review the meaning of this result. In the above model, the yield spread does not predict movements in output because the shape of the yield curve causes output to behave as it does; rather the yield curve is shaped as it is because it responds (through the rational expectations of the policymaker and the public) to the expected future values of economic variables. As is true with many financial variables that predict real variables, the ability to predict should be carefully distinguished from the ability to cause. The yield spread extracts expected inflation and output from the expected path of interest rates, which is determined by the central bank's policy reaction function. In other words, the yield spread does not tell us anything that the central 
bank and bondholding households don't implicitly already know - it merely summarizes the expectations of these economic agents. Given this, one might be tempted to take issue with Goodfriend (1998) and others who believe the predictive power of the yield spread should be used as a guide to monetary policy. After all, the shape of the yield curve is determined by a bond market operating with the same information set as the central bank. However, if the public and the central bank are operating with different information, unlike the model presented in this paper, then the central bank could actually gain new information from the yield spread regarding the public's expectation of the future course of real economic variables, information that could be useful in the setting of monetary policy. 
Table 1.

\begin{tabular}{c|c}
\hline Variable & \\
\hline$S$ & $0.89(0.01)$ \\
Fed funds & $-0.31(0.00)$ \\
\hline$R^{2}$ & 0.36 \\
\hline
\end{tabular}

Newey-West p-values in parentheses. Annualized output growth regressed on four-quarter lagged federal funds rate and the three-year less three-month spread.

Table 2a.

\begin{tabular}{c|c}
\hline Variable & \\
\hline$S$ & $1.07(0.00)$ \\
$d($ Fed funds $)$ & $-0.14(0.44)$ \\
\hline$R^{2}$ & 0.17 \\
\hline
\end{tabular}

Newey-West p-values in parentheses. Annualized output growth regressed on four-quarter lagged first difference of the federal funds rate and the three-year less three-month spread.

Table 2b.

\begin{tabular}{c|c}
\hline Variable & \\
\hline$S$ & $1.06(0.00)$ \\
VAR Residual & $-0.28(0.23)$ \\
\hline$R^{2}$ & 0.18 \\
\hline
\end{tabular}

Newey-West p-values in parentheses. Annualized output growth regressed on four-quarter lagged VAR residual-based measure of monetary policy and the three-year less three-month spread.

Table 2c.

\begin{tabular}{c|c}
\hline Variable & \\
\hline$S$ & $0.92(0.01)$ \\
Boschen-Mills index & $-0.50(0.04)$ \\
\hline$R^{2}$ & 0.22 \\
\hline
\end{tabular}

Newey-West p-values in parentheses. Annualized output growth regressed on four-quarter lagged BoschenMills index and the three-year less three-month spread. NB: Boschen and Mills use the convention that a positive number indicates easing policy, thus to be consistent with our other measures of policy stance we regress on the negative of the index. The index ends in 1996:1. 
Table 3. Data

\begin{tabular}{c|cc}
\hline Variable & Pre-Volcker & Volcker-Greenspan \\
\hline$S$ & $1.31(0.00)$ & $0.81(0.01)$ \\
Fed funds & $-0.82(0.00)$ & $-0.25(0.04)$ \\
\hline$R^{2}$ & 0.51 & 0.30 \\
\hline
\end{tabular}

Newey-West p-values in parentheses. Annualized output growth regressed on four-quarter lagged federal funds rate and the three-year less three-month spread.

Table 4. Simulations

\begin{tabular}{c|cc}
\hline Variable & Pre-Volcker & Volcker-Greenspan \\
\hline$S$ & $0.71(0.00)$ & $0.49(0.00)$ \\
Fed funds & $-0.11(0.03)$ & $-0.10(0.03)$ \\
\hline$R^{2}$ & 0.22 & 0.16 \\
\hline
\end{tabular}

Newey-West p-values in parentheses. Annualized output growth regressed on four-quarter lagged federal funds rate and the three-year less three-month spread.

Table 5. Simulations

Changing Each Taylor Parameter

\begin{tabular}{c|c|c|}
\hline Variable & Coefficient on Spread & $R^{2}$ \\
\hline Pre-Volcker & 0.71 & 0.22 \\
\hline With Volcker-Greenspan $\rho$ & 1.13 & 0.20 \\
\hline With Volcker-Greenspan $\beta$ & 0.46 & 0.16 \\
\hline With Volcker-Greenspan $\gamma$ & 0.43 & 0.22 \\
\hline Volcker-Greenspan & 0.49 & 0.16 \\
\hline
\end{tabular}

Newey-West p-values in parentheses. Annualized output growth regressed on four-quarter lagged federal funds rate and the three-year less three-month spread.

Middle three rows of the table show the effect of changing solely the Taylor parameter listed in the first column, keeping fixed the other parameters at their Pre-Volcker estimated values (first row). The last row lists the effect of the full estimated Volcker-Greenspan parameter set. 


\section{References}

[1] Allen, Franklin and Douglas Gale, "Optimal Financial Crises," Journal of Finance 53, 1998, pp. 1245-1284.

[2] Blanchard, Olivier J. and Charles Khan, "The Solution of Linear Difference Models Under Rational Expectations," Econometrica, 48-5, July, 1980, pp. 1305-1313.

[3] Boschen, John F. and Len O. Mills, "The Relation Between Money Market and Narrative Indicators of Monetary Policy," Economic Inquiry 23, January 1995, pp. 24-45.

[4] Clarida, Richard, Jordi Gali and Mark Gertler, "Monetary Policy Rules and Macroeconomic Stability: Theory and Some Evidence," Quarterly Journal of Economics, Vol. 115, No. 1, February 2000, pp. 147-180.

[5] Dotsey, Michael, "The Predictive Content of the Interest Rate Term Spread for Future Economic Growth," Federal Reserve Bank of Richmond Economic Quarterly, Summer 1998, Vol. 84, No. 3, pp. 31-51.

[6] Estrella, Arturo, "Monetary Policy and the Predictive Power of the Term Structure of Interest Rates," Federal Reserve Bank of New York, mimeo, November, 1998.

[7] Estrella, Arturo and Gikas A. Hardouvelis, "The Term Structure as a Predictor of Real Economic Activity," Journal of Finance, June 1991, pp.555-575.

[8] Estrella , Arturo and Frederic S. Mishkin, "Predicting U.S. Recessions: Financial Variables as Leading Indicators," Federal Reserve Bank of New York Research Paper No. 9609, May 1996. 
[9] Estrella, Arturo, Anthony P. Rodrigues and Sabastian Schich, "How Stable is the Predictive Power of the Yield Curve? Evidence from Germany and the United States," Federal Reserve Bank of New York Staff Report No. 113, September 2000.

[10] Goodfriend, Marvin, "Using the Term Structure of Interest Rates for Monetary Policy," Federal Reserve Bank of Richmond Economic Quarterly, Summer 1998, Vol. 84, No. 3, pp. 13-30.

[11] Hamilton, James D. and Dong Kim, "A Re-Examination of the Predictability of the Yield Spread for Real Economic Activity," NBER Working Paper No. 7954, Oct. 2000.

[12] Ireland, Peter, "Sticky-Price Models of the Business Cycle: Specification and Stability," Journal of Monetary Economics, Vol. 47, No. 1, February, 2001, pp. 3-18.

[13] Laurent, Robert, "An Interest Rate Based Indicator of Monetary Policy," Economic Perspectives, Federal Reserve Bank of Chicago, January/February 1988.

[14] Mishkin, Frederic S., "The Information in the Longer Maturity Term Structure About Future Inflation," Quarterly Journal of Economics, August 1990, pp.815-828.

[15] Newey, Whitney and Kenneth West, "A Simple, Positive Semi-definite, Heteroskedasticity and Autocorrelation Consistent Covariance Matrix," Econometrica, 55, 1987, pp. 703-708.

[16] Romer, Christina D., "Discussion" of "The Causes of American Business Cycles: An Essay in Economic Historiography," in "Beyond Shocks: What Causes Business Cycles?", Federal Reserve Bank of Boston Conference Series No. 42, 1998, pp. 60-64.

[17] Stock, James and Mark Watson, "New Indexes of Coincident and Leading Indicators," in Olivier Blanchard and Stanley Fischer, eds., NBER Macroeconomics Annual 4, 1989. 
[18] Temin, Peter, "The Causes of American Business Cycles: An Essay in Economic Historiography," in "Beyond Shocks: What Causes Business Cycles?", Federal Reserve Bank of Boston Conference Series No. 42, 1998, pp. 37-59. 